\title{
ANÁLISE DAS ÊNFASES FORMATIVAS DE MESTRADOS PROFISSIONAIS DESTINADOS A PROFESSORES DE MATEMÁTICA
}

\author{
AN ANALYSIS OF THE FORMATIVE EMPHASIS OF PROFESSIONAL MASTER DEGREES \\ DIRECTED TO MATHEMATICS TEACHERS \\ ANÁLISIS DE LOS ÉNFASIS FORMATIVOS DE MAESTRÍAS PROFESIONALES \\ DESTINADAS A PROFESORES DE MATEMÁTICA
}

Ana Leticia Losano ${ }^{\mathrm{i}}$

Dario Fiorentini

\begin{abstract}
RESUMO: Os mestrados profissionais representam, atualmente, uma importante e variada oportunidade formativa dentro da Educação Superior para os professores em exercício. Desde a sua criação, eles têm sido alvo de diversos debates, muitos deles ainda em vigência. Um ponto particularmente importante desses debates tem sido a discussão sobre as formas de organizar as propostas curriculares (sua estrutura e dinâmica, assim como as vinculações entre ensino e pesquisa) que melhor potencializem a articulação entre o mestrado profissional e a prática docente nas escolas dos professores-mestrandos. Buscando contribuir com estes debates, este artigo tem por objetivo descrever e analisar as maneiras em que é concebido o sujeito da formação e as ênfases formativas de quatro cursos de mestrado profissional destinados a professores de matemática no estado de São Paulo. Utilizando uma metodologia qualitativa, desenvolveu-se uma análise documental de diversos documentos oficiais produzidos e disponibilizados pelos quatro cursos. Os resultados mostram que, embora estejam destinados a professores de matemática, os quatro cursos concebem o professor-mestrando de maneiras diversas e privilegiam diferentes conhecimentos e aprendizagens docentes. Deste modo, os quatro cursos estabelecem diferentes níveis de articulação entre as atividades formativas organizadas dentro do mestrado e a prática docente nas escolas dos professores-mestrandos.
\end{abstract}

PALAVRAS-ChAVE: Mestrado profissional. Formação docente. Análise documental.

ABSTRACT: Nowadays, professional masters programs constitute an important and varied formative possibility inside Higher Education for in-service teachers. Since its origins, Professional Masters programs have been at the center of several debates. A particularly important point concerning those debates is the discussion about the ways of organizing the curriculum (its structure and dynamics as well as the relations between teaching and research) that better articulate the program with the practice of teaching in the school. In order to contribute to these debates, this article aims at describing and analyzing the ways in which the teacher is conceived and the formative emphasis of four professional masters programs directed to mathematics teachers in the São Paulo state. Using a qualitative methodology, we present a documentary analysis of diverse official documents produced and made available by the four programs. The results show that, although they are directed to mathematics teachers, the four programs conceive the teacher differently and establish different levels of articulation between the formative activities organized by the program and the teaching practice in the school.

KEYWORDS: Professional master programs. Teachers education. Qualitative research.

RESUMEN: En la actualidad, las maestrías profesionales representan una importante y variada oportunidad formativa dentro de la Educación Superior para profesores en servicio. Desde su creación estos cursos han sido objeto de diversos debates, muchos de ellos todavía vigentes. Un punto particularmente importante de estos debates ha sido la discusión sobre las maneras de organizar las propuestas curriculares (su estructura y dinámica,

Submetido em: 12/01/2018 - Aceito em: 25/01/2018 - Publicado em: 12/02/2018.

\begin{tabular}{l|l|l|l|l|l}
\hline (C) Rev. Inter. Educ. Sup. & Campinas, SP & v.4 & n.2 & p.278-307 & maio/ago. 2018
\end{tabular}


así como también las vinculaciones entre enseñanza e investigación) que mejor potencialicen la articulación entre las Maestrías Profesionales y la práctica docente en las escuelas de los profesores-maestrandos. Buscando contribuir con estos debates, este artículo tiene por objetivo describir y analizar las maneras en que es concebido el sujeto de la formación y los énfasis formativos de cuatro maestrías profesionales destinadas a profesores de matemática en el estado de San Paulo. Utilizando una metodología cualitativa, desarrollamos un análisis documental de diversos documentos oficiales producidos y disponibilizados por los cuatro cursos. Los resultados muestran que, aunque todos estén destinadas a profesores de matemática, las cuatro maestrías conciben al profesor-maestrando de maneras diversas y privilegian diferentes conocimientos y aprendizajes docentes. De este modo, los cuatro cursos establecen diferentes niveles de articulación entre las actividades formativas organizadas dentro de la maestría y la práctica docente en las escuelas de los profesores-maestrandos.

PALABRAS CLAVE: Maestrías profesionales. Formación docente. Investigación cualitativa.

\section{INTRODUÇÃO}

O presente trabalho faz parte de uma pesquisa em andamento situada no campo da formação de professores de matemática e focalizada em um espaço formativo particular: os mestrados profissionais (MP).

O compromisso das instituições de Ensino Superior com a formação de professores da Educação Básica tem sido uma temática debatida em diferentes momentos históricos do Brasil. Particularmente, os MP trazem um novo elemento a esses debates, visto que tendem a reforçar ou provocar o compromisso da Pós-Graduação com a qualificação docente (CAMPOS; GUÉRIOS, 2017). No contexto brasileiro, os MP destinados à formação de professores têm uma trajetória bastante curta, e sua implantação esteve marcada por resistências, impasses e desconfianças (ANDRÉ; PRINCEPE, 2017). Assim, seu papel no contexto da formação docente encontra-se em processo de consolidação.

Os objetivos, as orientações e as normas para credenciamento e avaliação dos MP foram definidos pela Capes através da Portaria Normativa No 17/2009 (BRASIL, 2009). Um dos objetivos para os MP, estabelecido no Artigo 4 dessa Portaria, visa "capacitar profissionais qualificados para o exercício da prática profissional avançada e transformadora de procedimentos, visando atender demandas sociais, organizacionais ou profissionais e do mercado de trabalho" (BRASIL, 2009, p. 20). A partir dessas orientações, os MP destinados a professores podem ser compreendidos como espaços de formação que tomam como foco a qualificação profissional dos docentes em exercício, considerando a especificidade do trabalho docente.

Passados nove anos da formulação dessas orientações, os MP constituem, hoje, uma importante possibilidade formativa dentro da Educação Superior, para os professores em geral e para o professor de matemática, em particular. Nessa direção, a plataforma Sucupira 
da Capes $^{2}$, em 05/01/2018, informava que havia 82 programas de MP aprovados e reconhecidos dentro da Área de Ensino e outros 47 na Área de Educação. Segundo Campos e Guérios (2017), a ampliação da oferta desses cursos é um importante indicador da legitimação que esses espaços formativos foram ganhando ao longo destes últimos anos. Além disso, os MP constituem ofertas formativas bastante variadas, sendo oferecidos por diferentes instituições de Educação Superior - tais como universidades, instituições de ensino e centros de pesquisa públicos e privados - ao longo do País, perseguindo diferentes metas e objetivos e tendo diferentes organizações curriculares. No atual cenário, onde os MP são um espaço formativo cada vez mais consolidado no contexto da Educação Superior, diversos autores ressaltam que é fundamental o desenvolvimento de pesquisas que analisem as produções, os impactos desses espaços formativos e as experiências que os professores em exercício estão vivenciando dentro deles (CAMPOS; GUÉRIOS, 2017; NERES; NOGUEIRA; BRITO, 2014).

A esse respeito, as palavras de Cochran-Smith e Lytle (1999, p. 249) parecem particularmente pertinentes:

\begin{abstract}
Existem concepções radicalmente diferentes sobre a aprendizagem do professor, incluindo imagens diversas do conhecimento; da prática profissional; das relações necessárias e/ou potenciais que existem entre ambas; dos contextos intelectuais, sociais e organizacionais que apoiam a aprendizagem do professor; e das maneiras nas quais essa aprendizagem está vinculada às mudanças educativas e às finalidades da educação. Diferentes concepções da aprendizagem do professor - porém nem sempre explicitadas - levam a ideias diferentes sobre como melhorar a formação do professor.
\end{abstract}

Assim, podemos pensar que atualmente, no Brasil, os diferentes cursos de MP destinados a professores são concebidos e sustentados por diferentes modos de compreender a aprendizagem, o conhecimento e a prática do professor. A esse respeito, não podemos deixar de mencionar que, dentro de nossa comunidade de formadores de professores, no âmbito da Educação Superior, ainda persistem muitas questões polêmicas e contraditórias sobre quais deveriam ser os espaços e as ênfases formativas desses cursos. Algumas dessas questões surgidas de nossa própria experiência e de aportes de outros autores (CARNEIRO, 2008; PIRES; INGLIORI, 2013; SOUSA, 2013) - são: Qual a caraterização de um MP destinado a professores de matemática? Quais são as visões de formação que sustentam essas iniciativas? Quem são os sujeitos aos quais estão destinadas essas propostas formativas? Que demandas formativas procuram atender? Como organizam a sua estrutura curricular a partir dessas visões e demandas? Quais são as contribuições que esses espaços formativos estão trazendo para as práticas de ensinaraprender ${ }^{3}$ dos professores-mestrandos nas escolas? Qual é a

\footnotetext{
${ }^{2}$ http://www.capes.gov.br/cursos-recomendados (Acesso em: 5 jan. 2018)

3 Empregamos a palavra composta "ensinaraprender" como uma forma de expressar "a complexidade e a dialética de como percebemos a relação entre o ensino e a aprendizagem" (CARVALHO; FIORENTINI, 2013, p. 11).

\begin{tabular}{|l|l|l|l|l|l} 
(c) Rev. Inter. Educ. Sup. & Campinas, SP & v.4 & n.2 & p.278-307 & maio/ago. 2018
\end{tabular}
}


contribuição que se espera da pesquisa dentro de um MP voltado à formação de professores? Qual deveria ser a natureza do Trabalho de Conclusão de Curso (TCC)? Como ele deveria ser elaborado? Que relações o TCC deveria ter com a prática docente nas escolas? Embora a pesquisa que atualmente estamos desenvolvendo procure elaborar respostas para estas questões, no presente texto iremos nos centrar em algumas delas. Concretamente, aqui desenvolveremos a descrição e a análise das maneiras como é concebido o sujeito da formação e das ênfases formativas de quatro cursos de MP destinados a professores de matemática ofertados no estado de São Paulo. Nossa análise apoiar-se-á em documentos Regulamentos, Editais de Seleção, Grades curriculares, Ementas, etc. - disponibilizados pelos quatro cursos. Na próxima secção descreveremos nossa perspectiva sobre a formação de professores e operacionalizaremos as ideias de ênfase formativa e de sujeito de formação que nortearam nossas análises. Na sequência, explicitaremos a perspectiva metodológica do estudo, detalhando quais foram os documentos que compuseram nosso corpus documental e os procedimentos metodológicos que desenvolvemos. A seguir, apresentaremos a descrição e a análise de cada um dos MP e finalizaremos com a discussão de nossos resultados e a indicação de alguns desafios a serem enfrentados pela comunidade de pesquisadores e professores do Ensino Superior em relação à formação de professores de matemática no âmbito dos MP.

\section{A FORMAÇÃO DO PROFESSOR EM EXERCícIO}

Nas últimas décadas, a formação do professor em exercício tem ganhado ampla relevância no campo da Educação Matemática, originando múltiplas e diversas pesquisas (BEDNARZ; FIORENTINI; HUANG, 2011; JAWORSKI, 2006, 2008; KIERAN; KRAINER; SHAUGHNESSY, 2013; MATOS; POWELL; SZTAJN, 2009, entre outras). Particularmente, esses estudos sugerem diversos modos de compreender o professor em exercício como sujeito da formação e discutem quais deveriam ser os conhecimentos e as práticas em torno dos quais organizar essa formação. Por exemplo, Kieran, Krainer e Shaughnessy (2013) sublinham a importância de organizar espaços formativos que estejam em ressonância com os interesses, as crenças, as emoções, o conhecimento e a prática dos professores. Na mesma direção, diversos pesquisadores (COCHRAN-SMITH; LYTLE, 1999; CRECCI, 2016; KIERAN; KRANIER; SHAUGHNESSY, 2013; WHITE et al., 2013) vêm sublinhando a importância de organizar oportunidades formativas em que os próprios professores possam teorizar sobre suas práticas de ensino, através da reflexão crítica sobre seu trabalho e sobre seu conhecimento. Assumindo uma perspectiva similar, André e Princepe (2017), Campos e Guérios (2017) e Pires e Ingliori (2013), entre outros, afirmam que os MP que se organizam em torno da análise e da indagação da prática diária dos professores em sala de aula, embasados em resultados de pesquisa, têm o potencial de encurtar as distâncias entre universidade e escola, entre teoria e prática.

\begin{tabular}{l|l|l|l|l|l} 
(C) Rev. Inter. Educ. Sup. & Campinas, SP & v.4 & n.2 & p.278-307 & maio/ago. 2018 \\
\hline
\end{tabular}


Desde nossa perspectiva, a experiência de trabalho em sala de aula faz com que o professor que decide se matricular em um MP chegue ao curso trazendo consigo um conjunto de conhecimentos e práticas. A partir dos aportes de Cochran-Smith e Lytle (1999), podemos considerar que o professor que inicia um MP possui um conhecimento para a prática, que desenvolveu durante a formação inicial. Esse corpo de conhecimentos estaria centrado nos conteúdos que o professor precisa saber para ensinar, assim como nas estratégias necessárias para escolher, construir, utilizar e avaliar diferentes representações desse conteúdo a ser ensinado aos estudantes. Mas o professor também chega ao mestrado com um conhecimento na prática, ou seja, um conhecimento experiencial que desenvolveu no próprio exercício profissional. Trata-se de um conhecimento situado (LAVE, 1996) nas particularidades da vida cotidiana nas escolas e nas salas de aula e que se manifesta nas ações, nas decisões e nos julgamentos que os professores desenvolvem na prática.

Assumir esta perspectiva envolve considerar e reconhecer que os professores não são apenas sujeitos que aprendem conhecimentos, mas são também produtores de conhecimentos. Esses conhecimentos - carregados de valores, finalidades e sentidos para os professores - são fundamentais para desenvolver suas práticas docentes. Contudo, eles podem se tornar naturais e válidos por si mesmos, em virtude da rotina e da naturalização do quotidiano escolar, o que ocultaria desvios, ideologias e relações de poder (FIORENTINI, 2013; FIORENTINI; CARVALHO, 2015). As oportunidades formativas que contribuem para problematizar e ressignificar os conhecimentos desenvolvidos para e na prática dos professores - utilizando como referência e/ou interlocução os saberes acadêmicos - possuem o potencial de desenvolver um conhecimento da prática. Dessa maneira, o conhecimento da prática se desenvolve quando os professores têm oportunidade de analisar, interpretar e criticar suas próprias práticas, assim como interpretar e interrogar as teorias e as investigações de outros professores e pesquisadores.

Desde esta perspectiva sobre os professores, seus conhecimentos e as possibilidades de problematizá-los, ressignificá-los e desenvolvê-los a partir de propostas formativas, interrogamos os quatro MP, a partir de dois focos analíticos. Em primeiro lugar, como são concebidos os sujeitos da formação, ou seja, como é concebido o professor-mestrando em cada curso. Isso inclui o público alvo e também as necessidades de formação desse sujeito que serão atendidas no MP. Em segundo lugar, analisamos as ênfases formativas dos cursos, ou seja, quais as aprendizagens docentes que cada curso valoriza e quais as oportunidades consideradas potenciais para desenvolver essas aprendizagens dentro de cada MP.

\section{DESENHO DA PESQUISA E METODOLOGIA}

Este trabalho faz parte de uma pesquisa qualitativa em andamento, enquadrada dentro do paradigma interpretativo (ROCKWELL, 2009). Ela toma por foco quatro cursos de mestrado

(c) Rev. Inter. Educ. Sup. Campinas, SP v. 4

n.2

p.278-307

maio/ago. 2018 
profissional destinados a professores de matemática e oferecidos no estado de São Paulo (Brasil). A pesquisa, cujos achados iniciais sustentam este artigo, tem por objetivo elaborar descrições aprofundadas desses quatro espaços formativos e desenvolver estudos de caso de professores de matemática egressos desses MP no período entre 2014 e 2016 . A decisão de considerar um período de três anos se deveu, em parte, a nossa capacidade para analisar o volume de documentos produzidos por cada mestrado (principalmente as dissertações defendidas). Sabemos que a eleição desse período não nos permite delinear o desenvolvimento histórico dos cursos, desde a sua criação até a atualidade. Mas, considerando que o foco principal da nossa pesquisa é a análise do desenvolvimento da identidade profissional a partir da participação em um MP e os possíveis impactos desses espaços formativos nas práticas de ensinaraprender matemática na escola, o período 20142016 é adequado para construir uma boa caraterização dos cursos na atualidade.

A seleção dos quatro programas procurou abarcar diferentes Áreas da CAPES em que existem MP destinados a professores de matemática, assim como priorizar programas mais antigos e com maior quantidade de egressos. Dessa maneira, escolhemos dois MP da área de Ensino, aqui chamados MP $\mathbf{1}^{4}$ e MP 2. Ambos são os MP de maior antiguidade no estado de São Paulo e, portanto, possuem um grande número de egressos. Da área de Matemática, elegemos um curso semipresencial, que chamaremos MP 3, vinculado a uma rede federal. A escolha orientou-se pelo fato de ser o maior MP no Brasil destinado a professores de matemática. Dada a envergadura desse MP, na presente pesquisa analisaremos somente um polo, que chamaremos Polo A. Finalmente, escolhemos um programa da área de Educação que, apesar de seu caráter generalista, possui fortes vínculos com a Educação Matemática. Neste artigo, o curso será chamado MP 4.

Aqui desenvolveremos uma análise documental, entendendo este procedimento analítico como

uma série de operações, que visa estudar e analisar um, ou vários documentos, buscando identificar informações factuais nos mesmos, para descobrir as circunstâncias sociais, econômicas e ecológicas com as quais podem estar relacionados, atendendo-se sempre às questões de interesse (KRIPKA; SCHELLER; BONOTTO, 2015, p. 245).

Desse modo, procuramos produzir novos conhecimentos a respeito do fenômeno estudado os MP como espaços de formação que possuem diferentes ênfases formativas e compreendem de maneira diversa o sujeito de formação -, a partir das perspectivas captadas nos seus documentos. Entendemos que os documentos "podem ser instrutivos para a compreensão das realidades sociais em contextos institucionais" (FLICK, 2007, p. 237), como é o caso dos MP.

\footnotetext{
${ }^{4}$ Esta pesquisa foi aprovada pelos respectivos Comitês de Ética na Pesquisa dos quatro cursos de MP, com a ressalva de manter sob sigilo os nomes das instituições envolvidas. Assim, todos os nomes utilizados neste trabalho são pseudônimos. Ademais, temos mantido sob sigilo as fontes de dados. Projeto CAAE $\mathrm{N}^{0}$ : 68159717.1.0000.5404.
}

(C) Rev. Inter. Educ. Sup Campinas, SP v. 4 n. 2 p. $278-307$ maio/ago. 2018 
Com a nossa análise, visamos compreender o conteúdo dos documentos elaborados a partir dos quatro MP escolhidos, mas também descobrir o que está por trás desses conteúdos, revelando as maneiras como cada um deles compreende o professor e a formação de professores. Desse modo, os documentos não são apenas uma fonte de informação, mas surgem em um contexto e fornecem informação sobre ele (LÜDKE; ANDRÉ, 1986).

\section{Procedimentos analíticos}

A primeira etapa da nossa análise envolveu a seleção e a caraterização dos documentos a serem analisados. Incluímos em nosso corpus um conjunto de documentos que os quatro MP disponibilizam em suas páginas web (sintetizados na Tabela 1). Assim, os documentos analisados são arquivos públicos, oficiais e de publicação aberta (FLICK, 2007). A consulta aos documentos se realizou no período compreendido entre março e maio de 2017.

Tabela 1. Corpus documental

\section{Documento}

\begin{tabular}{cc}
\hline MP 1 & $\begin{array}{r}\text { Regimento interno; grade curricular; ementa das disciplinas; edital de } \\
\text { seleção (2017); } 32 \text { dissertações defendidas no período 2014-2016 }\end{array}$ \\
MP 2 & Objetivos; grade curricular; ementa das disciplinas, edital de seleção \\
& (2017); e Dissertações defendidas no período 2014-2015 ${ }^{6}$. \\
MP 3 & Regimento interno; grade curricular; catálogo de disciplinas; editais de \\
& seleção (2012, 2013, 2014); normas acadêmicas; 42 dissertações \\
MP 4 & Regimento interno; grade curricular; ementas das disciplinas; editais de \\
& seleção $(2013,2014) ; 6$ dissertações defendidas no período 2014-2016. \\
\hline
\end{tabular}

Fonte: Os autores

A escolha destes documentos para compor nosso corpus documental não foi aleatória e justifica-se por dois motivos: em primeiro lugar, grande parte dos documentos analisados constitui o que Sacristán (1998) caracteriza como o "currículo prescrito" dos MP. Assim, sua análise revela quais conhecimentos e práticas devem ser desenvolvidos nesses espaços formativos. Em segundo lugar, porque esses documentos forneciam informações sobre os sujeitos da formação e/ou as ênfases formativas do MP, aspectos que constituem nossos focos analíticos.

A segunda etapa envolveu o desenvolvimento de processos analíticos sobre os documentos.

\footnotetext{
${ }^{5}$ No período 2014-2016 foram defendidas 33 dissertações na área Ensino da Matemática. Porém, a página web do MP 1 só disponibilizava 32 no momento em que a análise documental foi desenvolvida.

${ }^{6}$ As dissertações defendidas no ano 2016 não estavam disponíveis na página web do MP 2 no período em que desenvolvemos a análise documental.

\begin{tabular}{|l|l|l|l|l|l|}
\hline (C) Rev. Inter. Educ. Sup. & Campinas, SP & v.4 & n.2 & p.278-307 & maio/ago. 2018 \\
\hline
\end{tabular}
}


Visando desenvolver compreensões sobre os sujeitos da formação de cada MP, selecionamos informações vinculadas com o público alvo e com o perfil de professor que cada curso procura formar. Essas informações geralmente estavam expressas nos objetivos do MP e/ou nos editais de seleção.

Visando desenvolver compreensões sobre as ênfases formativas dos cursos, selecionamos informações vinculadas à estrutura curricular de cada um, focalizando as disciplinas oferecidas e a natureza e o conteúdo das dissertações. A análise das dissertações foi realizada a partir da leitura do resumo e das palavras-chave do trabalho, da exploração da tabela de conteúdos e da leitura do capítulo introdutório. Esse trabalho esteve direcionado, principalmente, a determinar qual é o papel formativo outorgado à dissertação dentro de cada MP e qual é a sua vinculação com as práticas de ensinaraprender matemática dos professores-mestrandos. Assim, buscamos verificar se a elaboração da dissertação comprometeu o autor na criação ou na adaptação de tarefas para sala de aula; se elas foram implementadas, efetivamente, nos cursos ministrados pelo autor ou por outros; e se o mestrando incluiu também algum tipo de análise ou reflexão posterior à implementação.

A análise das disciplinas que compõem a grade curricular dos MP foi efetuada a partir de suas ementas, as quais contêm, às vezes, referências bibliográficas. Este estudo busca delinear os diferentes conhecimentos que cada disciplina privilegia e qual a sua relação com a prática docente dos professores-mestrandos nas escolas. Para isso, seguimos as orientações de diversos modelos centrados no conhecimento do professor (CARRILLO et al., 2013; SHULMAN, 1986, 1987) e construímos três categorias gerais para descrever os conhecimentos que as disciplinas procuram desenvolver. A primeira categoria é o conhecimento matemático, ou seja, o conhecimento da disciplina que o professor ensina, podendo incluir os conceitos, os procedimentos e as práticas próprias da matemática. Chamamos a segunda categoria conhecimento pedagógico geral, que abarca os princípios e as estratégias pedagógicas gerais para a organização e a gestão da aula. A terceira categoria é o conhecimento pedagógico do conteúdo, ou seja, uma amálgama de conteúdo e pedagogia, incluindo conhecimentos sobre como formular e apresentar os tópicos, para torná-los compreensíveis para os alunos. Estas três categorias serviram como marco geral da análise, e o sentido concreto que cada uma delas adquire dentro de cada MP foi um ponto emergente da análise, isto é, não determinado previamente. Por exemplo, decorrerá de nossa análise a conclusão de ser o conhecimento matemático compreendido, dentro de determinado curso, como o conhecimento matemático acadêmico desenvolvido pela comunidade de matemáticos ou como conhecimento matemático vinculado às práticas escolares. Além disso, estivemos abertos a acrescentar outras categorias, caso fosse necessário. Também identificamos, em uma quarta categoria, aquelas disciplinas voltadas principalmente ao desenvolvimento da dissertação.

Visto que uma disciplina pode desenvolver vários tipos de conhecimentos, optamos por

\begin{tabular}{l|l|l|l|l|l}
\hline (C) Rev. Inter. Educ. Sup. & Campinas, SP & v.4 & n.2 & p.278-307 & maio/ago. 2018
\end{tabular}


representar essas categorias através de diagramas, conforme a Figura 1. Por exemplo, se na ementa de uma disciplina encontrávamos indícios de que ela visava ao desenvolvimento do conhecimento matemático e do conhecimento pedagógico do conteúdo, o nome dela era colocado na interseção dos círculos amarelo (utilizado sempre para nos referir ao conhecimento matemático) e rosado (utilizado para nos referir ao conhecimento pedagógico do conteúdo). Nos esquemas, as disciplinas obrigatórias foram ressaltadas em negrita. Assim, os esquemas permitiram visibilizar facilmente quantas disciplinas estavam incluídas em cada categoria, a qual categoria pertencem as disciplinas optativas e obrigatórias, se havia categorias vazias, se havia interseções vazias, etc.

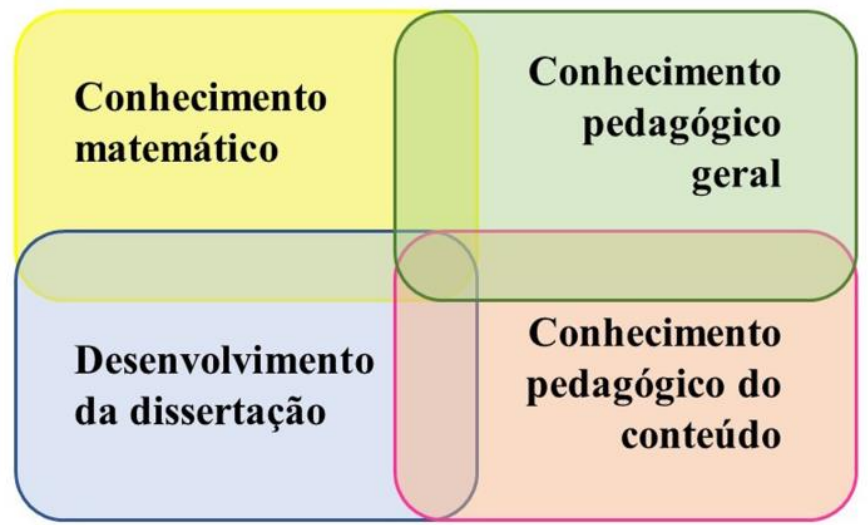

Figura 1. Esquema utilizado para categorizar as disciplinas de cada MP Fonte: Os autores

Esses esquemas resultaram de grande utilidade: em primeiro lugar, porque permitem mapear os conhecimentos e as aprendizagens que cada MP privilegia e procura desenvolver; em segundo lugar, porque nos permite perceber e discutir as relações entre os conhecimentos desenvolvidos dentro do MP e os conhecimentos e as práticas profissionais desenvolvidos pelos professores-mestrandos em sua atuação docente.

As próximas seções estão destinadas a apresentar os resultados da nossa análise para cada um dos MP selecionados.

\section{RESULTADOS}

\section{$O$ MP 1}

Este curso, ministrado por uma universidade pública, foi criado em 2008 dentro da área de Ensino. Ele está dividido em duas áreas de concentração: Ensino de Física e Ensino de Matemática ${ }^{7}$. Conforme informações contidas na página web do curso e também no último Edital de Seleção, o MP 1 é destinado a professores em exercício que ensinam matemática nos anos finais do Ensino Fundamental ou no Ensino Médio, possuindo diferentes titulações -

${ }^{7}$ Neste texto vamos focalizar o ensino de Matemática, que constitui o nosso campo de interesse.

\begin{tabular}{l|l|l|l|l|l} 
(C) Rev. Inter. Educ. Sup. & Campinas, SP & v.4 & n.2 & p.278-307 & maio/ago. 2018
\end{tabular}


Bacharel, Licenciado, Engenheiro, Contador, etc.- e que trabalham, preferencialmente, em escolas públicas.

Em relação às necessidades formativas dos professores que o curso procura atender, o Regimento Interno do MP 1 estabelece que o curso procura "possibilitar ao pós-graduando condições para o desenvolvimento de uma prática profissional transformadora, por meio da incorporação do método científico e da aplicação dos conhecimentos de novas técnicas e processos" (MP 1, 2008, Art. 1, §1,). Desse modo, o MP 1 se configura como um espaço que busca produzir mudanças na prática profissional dos professores-mestrandos, a partir de processos formativos em que o mestrando incorpora métodos - neste caso, o método científico - e aplica conhecimentos produzidos por outras pessoas em outros contextos.

A estrutura curricular do MP 1 estipula uma divisão dos créditos entre disciplinas (56) e o TCC (44), que recebe formato de Dissertação. Assim, dentro deste MP, as disciplinas são consideradas como oportunidades formativas de grande relevância. Elas estão divididas em disciplinas obrigatórias (cinco, no total) e optativas. O esquema resultante da categorização das disciplinas do curso é mostrado na Figura 2. Uma caraterística interessante deste mestrado é que existem disciplinas obrigatórias na área de concentração Ensino de Física, que são optativas para a área de concentração Ensino de Matemática, e vice-versa. Essa estrutura supõe, então, que disciplinas próprias do campo do Ensino de Física possam contribuir com a formação do professor de matemática. Tal caraterística fez com que, em nosso esquema, acrescentássemos uma categoria correspondente ao conhecimento da Física (vide círculo cinza, à esquerda da Figura 2).

A partir da análise do esquema, fica claro que este curso privilegia oportunidades para desenvolver o conhecimento matemático do professor-mestrando. As ementas de várias das disciplinas desta categoria consistem, principalmente, em uma lista de tópicos matemáticos a serem tratados, incluindo, em alguns casos, "aplicações" o que contribuiria para que o professor-mestrando compreenda algumas relações da matemática com outros campos de saber. A disciplina "História das Ciências da Natureza e da Matemática" foi classificada na interseção entre o conhecimento matemático e o conhecimento da Física, visto que sua ementa se centra na apresentação do desenvolvimento da estrutura das disciplinas e das práticas que foram e são atualmente legitimadas pela comunidade acadêmica. Dessa maneira, poderíamos dizer que o conhecimento matemático que o MP 1 procura desenvolver no professor-mestrando está vinculado à matemática acadêmica, abarcando desde conteúdos matemáticos avançados até oportunidades para estudar as práticas e a estrutura da disciplina. 


\section{Estudos avançados de fisica clássica, Estudos avançados de fisica moderna e contemporânea, Conceitos de astronomia e astrofisica aplicados ao ensino médio e fundamental, Tópicos de fronteira em fisica, Fisica na web \\ Conhecimento matemático $\uparrow$ \\ Historia das ciências da natureza e da matemática \\ Geometria - Teoria e experimentação, Análise Matemática para licenciados, Teoria dos números, Matemática discreta, Algebra linear para professores do ensino médio, Elementos de Álgebra Moderna \\ Ensino de ciências e matemática através da resolução de problemas, Ensino de ciências e matemática através da modelagem de fenómenos naturais, Epistemologia e ensino de ciências e matemática \\ Oficinas pedagógicas e jogos em matemática \\ Tecnologias da informação para o ensino de ciências e matemática, Instrumentação para 0 ensino de ciências e matemática \\ Teorias de ensino e aprendizagem \\ Fundamentos metodológicos da educação em ciências e matemática, metodologia de pesquisa em ensino de ciências e matemática \\ Conhecimento pedagógico do conteúdo \\ Desenvolvimento da dissertação}

Figura 2. Esquema das disciplinas oferecidas pelo MP 1 Fonte: Os autores

As disciplinas categorizadas na interseção entre o conhecimento matemático, o conhecimento da Física e o conhecimento pedagógico do conteúdo priorizam diversas práticas utilizadas para produzir conhecimento matemático - incluindo a resolução de problemas e a modelagem - e tecem também reflexões sobre o ensino e a aprendizagem da matemática através dessas práticas, o que estaria dirigido a desenvolver o conhecimento pedagógico do conteúdo. Assim, o conhecimento pedagógico do conteúdo que o MP 1 procura desenvolver estaria ligado ao estudo de ferramentas para o ensino inspiradas tanto em práticas provenientes da matemática como disciplina acadêmica - resolução de problemas e modelagem - como em práticas pedagógicas como os jogos.

Duas disciplinas foram categorizadas como pertencendo à tripla interseção entre os conhecimentos matemático, pedagógico do conteúdo e pedagógico geral, visto que ambas incluem a elaboração, a implementação e/ou a análise de tarefas em sala de aula - a primeira em ambientes informatizados, e a segunda dentro de um estágio em que também são utilizados registros reflexivos da prática docente desenvolvida. Do nosso ponto de vista, atuar em sala de aula necessariamente envolve a mobilização de, pelo menos, esses três tipos de conhecimentos. Essas duas disciplinas são de caráter obrigatório, o que indica que, no MP 1, essas oportunidades de aprendizagem docente são tão valorizadas quanto as aprendizagens em geometria e análise matemática - outras duas disciplinas obrigatórias.

\begin{tabular}{l|l|l|l|l|l}
\hline (C) Rev. Inter. Educ. Sup. & Campinas, SP & v.4 & n.2 & p.278-307 & maio/ago. 2018
\end{tabular}


A disciplina "Teorias de ensino e aprendizagem" foi categorizada na interseção entre o conhecimento pedagógico geral, o conhecimento pedagógico do conteúdo e o desenvolvimento da dissertação. Essa escolha justifica-se porque ela visa apresentar perspectivas teóricas para compreender o ensino e a aprendizagem, utilizando-as como ferramentas para a objetivação didática do ensino de ciências e matemática e colaborar na seleção das abordagens teóricas dos projetos de pesquisa dos professores-mestrandos. Mais duas disciplinas estão voltadas ao desenvolvimento da dissertação.

No período 2014-2016 foram defendidas 33 dissertações na área Ensino da Matemática, e aproximadamente $79 \%$ delas (26) envolveram a elaboração e a implementação de atividades para sala de aula. Muitos desses trabalhos começam realizando uma descrição histórica e curricular do tópico matemático a ensinar, continuam com a descrição de um conjunto de tarefas para sala de aula e, a seguir, descrevem a sua implementação. Quase todos eles finalizam com uma análise da experiência. Como perspectivas didático-metodológicas que embasam tanto a construção das tarefas como a sua implementação e análise, a Engenharia Didática possui um peso importante. A perspectiva da resolução de problemas, as atividades orientadoras da aprendizagem e, em menor medida, a modelagem matemática também são utilizadas.

Foi possível verificar que, em 15 dessas 26 dissertações, as atividades foram desenvolvidas nas salas de aula em que os professores-mestrandos lecionam regularmente. A motivação que deu origem à problemática de estudo das 15 dissertações surgiu de suas experiências como docentes, sendo mais frequente a constatação das dificuldades de seus alunos na aprendizagem do tópico matemático que é o foco da proposta de sala de aula. As 11 dissertações restantes não deixam claro se a proposta foi, ou não, implementada em sala de aula do professor-mestrando.

As sete dissertações que não envolveram a elaboração, a implementação e a análise de uma proposta didática têm por foco diversas problemáticas: três delas analisam diferentes aspectos do processo de aprendizagem dos alunos a partir das noções de memorização, registros de representação semiótica e uso de software; uma dissertação desenvolve a análise de material curricular e outra elabora materiais manipulativos; uma outra toma por foco a prática da mestranda como formadora de professores, estudando como as orientações de uma diretoria de ensino contribuem com a formação dos professores e os auxiliam na sua atuação em sala de aula.

A partir da análise realizada, podemos interpretar que o MP 1 sustenta e legitima duas ênfases formativas: a primeira busca favorecer aprendizagens docentes ligadas a um conhecimento matemático cujas formas e domínios decorrem da matemática acadêmica, sendo geralmente produzido por matemáticos. O MP 1 oferece algumas oportunidades para vincular esse conhecimento da matemática com a sala de aula, através da apresentação de

\begin{tabular}{l|l|l|l|l|l}
\hline (C) Rev. Inter. Educ. Sup. & Campinas, SP & v.4 & n.2 & p.278-307 & maio/ago. 2018 \\
\hline
\end{tabular}


estratégias e práticas de ensino consideradas adequadas pela sua relação com o desenvolvimento da própria matemática como disciplina - resolução de problemas, modelagem matemática, uso da história da matemática -, assim como também pelo seu valor didático: jogos. Essa ênfase, portanto, privilegia a aprendizagem de conhecimentos para a prática, conforme Cochran-Smith e Lytle (1999), o que é fortemente mediado e estruturado pela matemática acadêmica.

A segunda ênfase do MP 1 consiste em valorizar os saberes experienciais que os professoresmestrandos desenvolveram na prática, não no sentido de validá-los, mas para interrogá-los e problematizá-los através da reflexão e da investigação. A dissertação e as disciplinas que envolvem a realização de atividades em sala de aula seriam os espaços considerados com maior potencial para desenvolver essas aprendizagens. Os conhecimentos para a prática mencionados anteriormente - principalmente algumas perspectivas pedagógicas, como a Engenharia Didática - são também trazidos a esses espaços como ferramentas que ajudam a estruturar e subsidiar a reflexão dos professores-mestrandos. Poderíamos dizer, então, com base em Cochran-Smith e Lytle (1999), que o MP 1 também oferece oportunidades para os professores desenvolverem aprendizagem de conhecimentos da prática docente.

\section{O MP 2}

Dos quatro cursos selecionados para este estudo, o MP 2 é o mais antigo, tendo sido criado em 2004. Ele também pertence à área de Ensino e é ministrado por uma universidade particular. A área de concentração do curso é Ensino de Ciências e Matemática. É um MP amplo, no que diz respeito a seu público alvo. Assim, no Edital de Seleção para o ano 2017 ficou estabelecido que poderiam participar do processo professores e outros profissionais que atuavam na área de Ensino de Ciências e Matemática em qualquer nível de ensino. Portanto, os professores aos quais está destinado o MP 2 ensinam Física, Química, Biologia e/ou Matemática no Ensino Médio, Fundamental ou Infantil, podendo ter uma formação inicial com uma base pedagógica (cursos de Licenciatura) ou não (Bacharelados).

Em relação ao perfil do aluno do MP 2, os objetivos enunciados na página web enfatizam a formação de um professor pesquisador que, em primeiro lugar, possa atuar na formação de outros docentes em diferentes níveis e contextos. Desde esta perspectiva, o MP 2 se configura como um espaço orientado à formação de formadores. Mas o perfil do professor pesquisador é enfatizado, em segundo lugar, como um "profissional que atue de forma autônoma e contribua para a utilização e divulgação de pesquisas da área em situação real de ensino" (MP 2, s.d., on-line). Desde esta outra perspectiva, este curso se configura como um espaço orientado à formação de um docente que, a partir de seus próprios critérios e realidades, recupere conhecimentos provenientes das pesquisas em educação em ciências e matemática e os coloque a serviço de sua prática profissional, contribuindo para sua disseminação em 
diversos âmbitos de trabalho. Assim também, outro objetivo do MP 2 ressalta que este espaço formativo considera a pesquisa em sua relação com a prática dos professores, ou seja, almeja que essa pesquisa possa contribuir para o desenvolvimento profissional dos professoresmestrandos.

Este é um curso que, na sua estrutura curricular, oferece uma variedade de oportunidades de aprendizagem. Assim, o professor-mestrando deve obter créditos distribuídos em disciplinas, seminários, estágios de docência supervisionada, participação efetiva em grupos de pesquisa e atividades de orientação do TCC.

Dentro da estrutura curricular, as disciplinas dividem-se entre obrigatórias e eletivas. As disciplinas obrigatórias são quatro e, segundo a página web do curso, estão focadas na produção do conhecimento científico e da prática docente. As eletivas estão divididas em três blocos: o primeiro está formado por disciplinas centradas no conteúdo específico das áreas de conhecimento do programa. Assim, o professor-mestrando deverá eleger três disciplinas relacionadas com a área específica em que atua (Física, Matemática, Biologia ou Química). O segundo bloco é composto por disciplinas de caráter pedagógico, abarcando problemáticas tais como currículo, avaliação, formação docente e políticas públicas. O professor-mestrando deverá escolher duas desse bloco. As disciplinas do terceiro bloco, das quais o professormestrando deverá escolher uma, abordam tópicos vinculados com as metodologias de ensino. O esquema resultante da análise das disciplinas mostra-se na Figura 3.

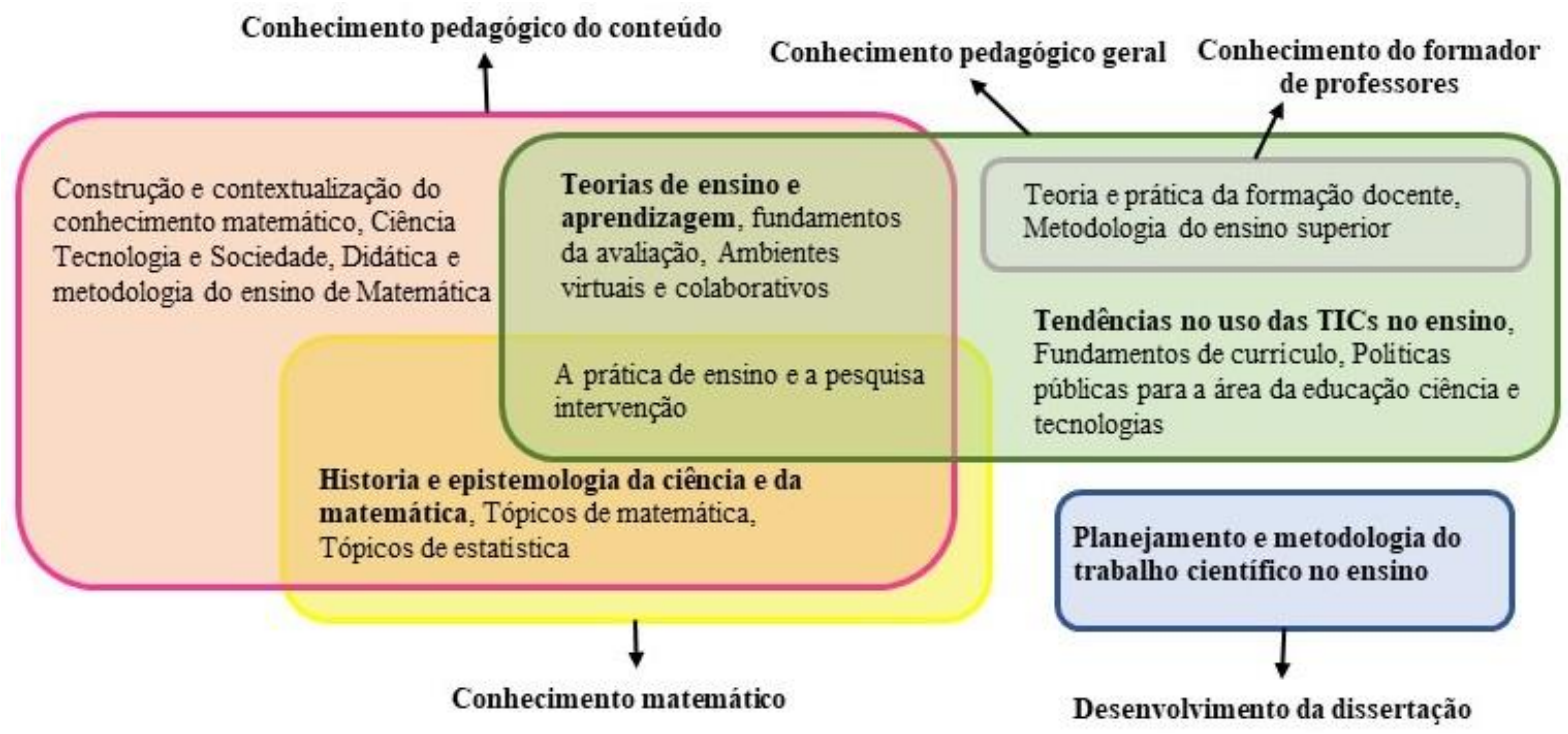

Figura 3. Esquema das disciplinas oferecidas pelo MP 2

Fonte: Os autores

Como podemos apreciar na Figura 3, na grade curricular do MP 2 o conhecimento matemático aparece sempre vinculado ao conhecimento pedagógico do conteúdo. Assim, três disciplinas foram categorizadas como pertencentes à interseção entre essas duas categorias,

\begin{tabular}{l|l|l|l|l|l} 
(C) Rev. Inter. Educ. Sup. & Campinas, SP & v.4 & n.2 & p.278-307 & maio/ago. 2018 \\
\hline
\end{tabular}


visto que abordam de maneira inter-relacionada os tópicos a ensinar, as dificuldades dos alunos e as formas de apresentar ou explorar conteúdos matemáticos em sala de aula. Um ponto interessante para destacar é que os conteúdos nelas incluídos se referem principalmente àqueles ensinados no Ensino Fundamental e Médio. Desse modo, poderíamos apresentar a hipótese de que a matemática que é valorizada no MP 2 é a matemática escolar.

Três disciplinas foram caraterizadas como voltadas a desenvolver exclusivamente o conhecimento pedagógico do conteúdo, visto que focalizam a exploração de diversas abordagens para ensinaraprender matemática. A disciplina denominada "A prática de ensino e a pesquisa intervenção" encontra-se na interseção entre os três tipos de conhecimentos, pois apresenta a pesquisa intervenção como um desafio e como uma possibilidade para a construção da identidade do professor pesquisador e propõe, ao professor-mestrando, o planejamento, a execução e a avaliação desse tipo de projeto na realidade escolar. Outras três disciplinas foram categorizadas na interseção entre o conhecimento pedagógico do conteúdo e o conhecimento pedagógico geral. Elas analisam as teorias da aprendizagem, o uso das tecnologias e a avaliação, em seus fundamentos, dimensões e transformações além das suas contribuições para o ensino de matemática.

No que se refere ao conhecimento pedagógico geral, há cinco disciplinas oferecidas neste MP. Três delas abordam as tendências no uso das tecnologias, o curriculum e as políticas educativas. As outras duas, que concretizam o objetivo de formar formadores de professores, foram agrupadas em uma nova categoria, direcionada a desenvolver os conhecimentos específicos que esses profissionais requerem. Uma última disciplina procura contribuir para o desenvolvimento do TCC e centra seu foco de estudo da metodologia do trabalho científico, concebendo-a como uma ferramenta para a análise do ensino.

No MP 2, o TCC assume uma forma dupla: como dissertação e como produto educacional. Os produtos educacionais vinculados às dissertações são textos geralmente mais curtos, cujo principal conteúdo são, na maioria dos casos, tarefas para sala de aula, originadas a partir da dissertação. Esses produtos parecem ter como objetivo principal proporcionar subsídios para outros professores. No período compreendido entre 2014 e 2015, foram defendidas 15 dissertações centradas em problemáticas vinculadas ao campo da Educação Matemática. Nove delas envolveram a elaboração de tarefas para sala de aula, e, dessas 9, 7 tomaram por foco de estudo uma problemática emergente da prática profissional do professor-mestrando. Todas as atividades foram desenvolvidas em sala de aula e, em 8 dissertações, as tarefas tiveram lugar na sala de aula em que o professor-mestrando leciona regularmente. Todas as dissertações também desenvolvem uma análise do processo de ensino e aprendizagem, muitas vezes, trazendo as produções dos estudantes e analisando suas dificuldades e seus avanços. Outras quatro dissertações foram elaboradas por professores-mestrandos que atuam como formadores de professores, e suas problemáticas emergiram de suas práticas docentes na Educação Superior. As duas dissertações restantes envolvem análises vinculadas a diferentes

\begin{tabular}{l|l|l|l|l|l}
\hline (c) Rev. Inter. Educ. Sup. & Campinas, SP & v.4 & n.2 & p.278-307 & maio/ago. 2018 \\
\hline
\end{tabular}


materiais curriculares.

Existe mais um ponto a destacar a respeito das oportunidades de aprendizagem que o MP 2 oferece: este curso institui um espaço obrigatório, chamado Estágio Supervisionado, onde os professores-mestrandos vinculam suas dissertações e/ou conhecimentos desenvolvidos nas disciplinas com a prática docente em sala de aula. $\mathrm{O}$ estágio supervisionado deve desenvolver-se depois de definir o tema de trabalho de investigação e, na medida do possível, nos ambientes escolares onde os professores-mestrandos já atuam.

A partir dessa análise, podemos dizer que o MP 2 caracteriza-se por apresentar uma ênfase formativa centrada na aprendizagem de conhecimentos fortemente ligados à prática de ensinaraprender matemática nas escolas. Em alguns casos, tratar-se-ia de um conhecimento para a prática, destinado a brindar os professores com conhecimentos disciplinares e pedagógico-didáticos desenvolvidos por outros - educadores, educadores matemáticos -, $\mathrm{o}$ que poderia ajudar a melhorar suas práticas. Contudo, o MP 2 também cria importantes espaços onde esses conhecimentos podem ser utilizados como ferramentas para que os professores-mestrandos elaborem questionamentos sobre suas práticas e interpretações sobre suas atuações e analisem suas aulas desde uma perspectiva indagativa. Isso permitiria recuperar, dentro do MP, o conhecimento na prática dos professores e constituir oportunidades de aprendizagem com uma ênfase no desenvolvimento do conhecimento da prática. Algumas das oportunidades privilegiadas para desenvolver essas aprendizagens parecem residir especialmente no Estágio Supervisionado, na dissertação e na disciplina chamada "Prática de ensino e pesquisa intervenção".

\section{O MP 3}

Este curso, filiado à área de Matemática, iniciou as suas atividades em 2011. Trata-se de um programa semipresencial de alcance nacional, coordenado por uma comunidade de matemáticos e integrado por uma rede nacional de Instituições de Ensino Superior que se constituem como polos. O MP 3 possui cinco áreas de concentração, quatro vinculadas à matemática e uma, chamada Ensino da Matemática, que trata das formas e das estratégias de ensino-aprendizagem da matemática.

Dos quatro mestrados selecionados, este é o mais específico em termos do seu público alvo. Está destinado a professores de matemática em exercício na Educação Básica, principalmente aqueles que atuam na escola pública, podendo ter formações iniciais variadas, como Licenciado e/ou Bacharel em Matemática, Contador, Engenheiro, etc. O objetivo do MP 3 é "proporcionar ao aluno formação matemática aprofundada, relevante ao exercício da docência em matemática no Ensino Básico, visando dar ao egresso, qualificação certificada para o exercício da profissão de professor de Matemática" (MP 3, 2014, Art. 2). Desde esta perspectiva, o MP 3 visa atender o que parece uma necessidade formativa específica dos 
professores de matemática: desenvolver o domínio aprofundado de conteúdos matemáticos, necessário para sua prática profissional. Entretanto, o programa não explicita o que entende por "domínio aprofundado" do conteúdo matemático e nem o que seria o "conteúdo relevante para o ensino básico".

Por ser um curso semipresencial, parte das oportunidades de aprendizagem que o MP 3 disponibiliza está mediada pelas tecnologias do ensino a distância (como gabaritos, videoaulas, ambientes virtuais de aprendizagem, etc.). As atividades presenciais são organizadas por cada polo, sendo as provas realizadas obrigatoriamente de modo presencial. A estrutura curricular do curso distribui os créditos em disciplinas, oito obrigatórias e duas eletivas. Um ponto importante a destacar é que, no MP 3, o TCC é considerado como uma disciplina obrigatória. Desse modo, as disciplinas são consideradas como as oportunidades formativas que possuem maior potencial para desenvolver as aprendizagens privilegiadas no MP 3. O esquema resultante da análise de cada uma delas apresenta-se na Figura 4.

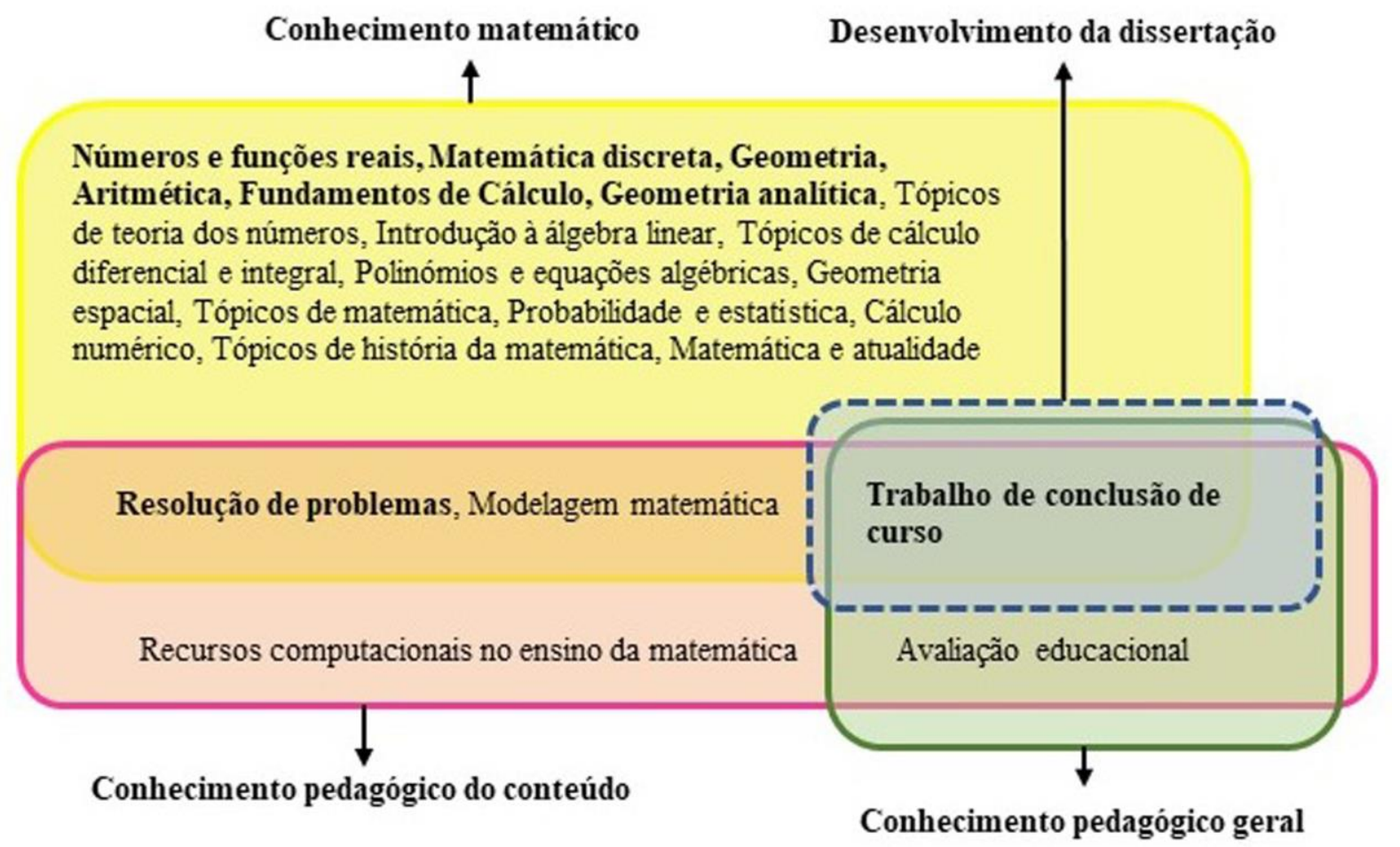

Figura 4. Esquema das disciplinas oferecidas pelo MP 3 Fonte: Os autores

Como revela a Figura 4, o MP 3 privilegia as disciplinas voltadas a desenvolver o conhecimento matemático. Muitas das ementas são formadas por uma lista de tópicos matemáticos que abarcam diversas áreas da matemática. Desde nosso ponto de vista, esta estrutura curricular - em que seis das oito disciplinas obrigatórias pertencem a esta categoria - está em consonância com o objetivo do curso de formar os professores no domínio

\begin{tabular}{l|l|l|l|l|l}
\hline (C) Rev. Inter. Educ. Sup. & Campinas, SP & v.4 & n.2 & p.278-307 & maio/ago. 2018 \\
\hline
\end{tabular}


aprofundado de conteúdos matemáticos. Os conteúdos matemáticos tratados em algumas dessas disciplinas podem vincular-se com aqueles incluídos nos currículos do Ensino Fundamental e Médio, enquanto, em outras, os conteúdos parecem próprios de cursos de matemática para o Ensino Superior. Ademais, nas ementas aparecem pouquíssimas referências à construção de vinculações entre esses conhecimentos matemáticos e a matemática escolar que o professor desenvolve durante sua prática profissional. Dessa maneira, poderíamos dizer que, no MP 3, o conhecimento matemático que é considerado valioso para o professor aprender é a matemática acadêmica com ênfase em seu rigor formal.

Duas disciplinas foram categorizadas na interseção entre o conhecimento matemático e o conhecimento pedagógico do conteúdo. Em relação ao conhecimento matemático, ambas têm por foco a resolução de problemas e a modelagem como formas de fazer e proceder em matemática. Em relação ao conhecimento pedagógico do conteúdo, as disciplinas propõem discutir estratégias de ensino baseadas nessas práticas matemáticas particulares. A disciplina "Recursos computacionais no ensino de matemática" foi caraterizada como direcionada a desenvolver o conhecimento pedagógico do conteúdo, visto que está centrada no estudo e na seleção de recursos tecnológicos para o ensino da matemática. Uma disciplina foi localizada na interseção entre o conhecimento pedagógico do conteúdo e o conhecimento pedagógico geral, porque ela trabalha com a avaliação em termos gerais - quando, o que, por que avaliar; o sistema de avaliação da Educação Superior; a construção de instrumentos de avaliação - e também traz análises de provas concretas como o ENEM. É importante ressaltar que nenhuma disciplina foi caraterizada como pertencente somente à categoria conhecimento pedagógico geral.

Finalmente, a disciplina obrigatória chamada "Trabalho de Conclusão de Curso", instituída na grade curricular como o espaço onde o professor-mestrando desenvolve sua dissertação, merece uma menção especial. A ementa da disciplina é a seguinte:

Disciplina dedicada a apoiar a elaboração de trabalho sobre tema específico pertinente ao currículo de Matemática do Ensino Básico e que tenha impacto na prática didática em sala de aula. Cada trabalho é apresentado na forma de uma aula expositiva sobre o tema do projeto e de um trabalho escrito, com a opção de apresentação de produção técnica relativa ao tema. (MP 3, 2016, p. 17)

Visto que, nesta citação, o trabalho dentro da disciplina implicaria um impacto na sala de aula através do desenvolvimento de um tema vinculado com o currículo de Matemática, decidimos colocá-la, dentro de nosso esquema, na interseção entre os três tipos de conhecimentos, já que consideramos que a atuação em sala de aula envolve mobilizar, no mínimo, esses três tipos de conhecimentos. Contudo, na ementa não fica claro o que seria um "tema" nem o que significa ter "impacto na sala de aula". Particularmente, não fica estabelecido se a elaboração da dissertação implica o desenvolvimento de algum tipo de atividade em sala de aula ou não. Por esse motivo, o círculo azul onde está incluída essa disciplina no esquema da Figura 4 possui 
borda de traço descontínuo.

Algumas destas dúvidas podem ser esclarecidas a partir da análise das 42 dissertações defendidas dentro do Polo A no período compreendido entre 2014 e 2016. No que diz respeito aos motivos que levaram os professores-mestrandos a escolher a problemática da sua dissertação, podemos dizer que eles estão, na grande maioria dos casos, fortemente vinculados com a própria matemática, procurando aplicar a matemática acadêmica na prática escolar. Outra motivação é a elaboração de material que ajude a estudar tópicos presentes nos vestibulares. O uso da história da matemática para o ensino de certos tópicos matemáticos é também mencionado como um fator motivador de 6 dissertações. Outras seis das 42 dissertações foram elaboradas tomando por foco problemáticas originadas na prática docente dos professores-mestrandos e vinculadas com as dificuldades que percebiam em seus alunos.

Segundo a maneira como estão estruturados, os trabalhos podem ser divididos em três grandes categorias: a primeira agrupa 9 dissertações que assumem o formato de um livro acadêmico centrado no desenvolvimento de algum tópico matemático. Esses trabalhos possuem um formato muito parecido com os livros tradicionais utilizados nas disciplinas de matemática no Ensino Superior. A segunda categoria agrupa 28 dissertações que dedicam vários capítulos ao desenvolvimento de um tópico matemático, geralmente começando por uma perspectiva histórica e seguindo uma estrutura similar àquelas incluídas na primeira categoria, porém estas têm como particularidade a inclusão, no último capítulo, de algum tipo de proposta de atividades para sala de aula que variam entre: lista de problemas e/ou exercícios; problemas resolvidos em detalhe; enunciado de tarefas seguidas de comentários para o professor; tarefas de construção, utilizando materiais manipulativos ou software; jogos e/ou aplicativos; atividades investigativas e/ou projetos; roteiros de explicações de um conteúdo matemático. A terceira categoria agrupa 5 dissertações, cujo eixo organizador é uma tarefa para sala de aula. Assim, 2 delas apresentam e desenvolvem matematicamente projetos e/ou experimentos para trabalhar determinados conteúdos matemáticos. As outras 3, além de apresentar a tarefa, descrevem a sua implementação e realizam uma análise da experiência.

Das 42 dissertações, 9 descrevem atividades que foram efetivamente implementadas em sala de aula - sendo que em apenas 3 delas o contexto foi a sala de aula onde o professormestrando leciona habitualmente. Em 7 dissertações não fica completamente esclarecido se houve ou não implementação. Ou seja, cerca de $62 \%$ das dissertações (26) não envolveram a realização de atividades em sala de aula. Podemos concluir que, embora a ementa da disciplina destaque que o tema do TCC deve ter impacto na prática em sala de aula, as dissertações constituem-se como uma oportunidade de aprendizagem que tem por foco principal o estudo matemático de algum tópico de interesse para o professor-mestrando e deixam em segundo plano o desenho e a realização de atividades em sala de aula.

A análise realizada permite concluir que a ênfase formativa do MP 3 encontra-se no conhecimento matemático acadêmico, desenvolvido por matemáticos na universidade. $\mathrm{O}$

\begin{tabular}{l|l|l|l|l|c}
\hline (C) Rev. Inter. Educ. Sup. & Campinas, SP & v.4 & n.2 & p.278-307 & maio/ago. 2018 \\
\hline
\end{tabular}


discurso sobre os professores que parece sustentar esta perspectiva é aquele que estabelece que "o bom professor é aquele que possui uma boa base de conhecimentos matemáticos avançados". A análise da estrutura curricular parece revelar que este curso oferece poucas oportunidades para que esse conhecimento matemático se conecte, de fato, com o mundo da prática docente nas escolas. Assim, a reflexão a respeito de como o conhecimento matemático aprofundado adquirido dentro do MP pode auxiliar no ensino dos conteúdos incluídos no currículo do Ensino Básico e a análise de estratégias didático-pedagógicas adequadas para ensinar esses conteúdos - o que envolveria o desenvolvimento do conhecimento para a prática docente - parecem ficar por conta e iniciativa dos professores-mestrandos. Nessa mesma direção, parece difícil que dentro do MP 3 os professores-mestrandos encontrem oportunidades para tomar, analisar e problematizar o conhecimento que desenvolveram na prática.

\section{$O$ MP 4}

Dentro da área de Educação, o MP 4 é oferecido por uma universidade pública e começou a funcionar em 2014. Com relação ao público alvo, o MP 4 é o mais abrangente dos quatro selecionados. Assim, fica estabelecido no último Edital de Seleção para a turma 2017 que poderão inscrever-se portadores de diploma obtido em qualquer curso superior de Licenciatura Plena. Embora os outros cursos analisados mencionem que estão destinados a professores em exercício, o MP 4 é o único que considera este ponto como requisito de admissão. Assim, além da titulação, é exigido que os postulantes ao MP 4 comprovem que possuem experiência docente de, no mínimo, dois anos e que, no momento da inscrição, se encontravam atuando na Educação Básica. Podemos dizer, então, que o MP 4 está destinado a professores de todas as áreas da Educação Básica, os quais, desde a sua formação inicial, escolheram tornar-se professores e chegaram ao mestrado com uma formação didáticopedagógica prévia. Uma marca caraterística do MP 4 poderia ser, então, o convívio com professores de diversas disciplinas, cujo ponto em comum são as suas preocupações sobre a educação, o ensino e a aprendizagem que emergiram durante as suas experiências na prática docente.

Em relação às necessidades formativas que o MP 4 procura atender, na página web consta que o curso pretende oferecer uma "formação acadêmica situada na prática profissional de docentes que atuam nas diversas áreas de conhecimento" e acrescenta que o MP 4 "pretende favorecer a melhor compreensão, por parte dos professores em exercício, dos princípios epistemológicos que sustentam suas ações" (MP 4, s.d., on-line). A partir dessas ideias, podemos dizer que as metas deste curso estabelecem vinculações profundas entre a formação do professor e a sua prática profissional - a formação que se oferece no curso está situada na prática do professor. Partindo dessa natureza situada, o curso procura desenvolver, nos professores, reflexões em torno dos princípios nos quais está embasado seu trabalho docente. 
Poderíamos concluir, então, que o MP 4 procura se constituir como um espaço formativo onde os professores possam considerar, refletir e problematizar o conhecimento que desenvolveram na prática docente nas escolas. Nessa direção, o Regimento Interno do MP 4 estabelece os objetivos do curso, entre os quais destacamos:

2) promover a parceria entre escola e universidade, de forma que a escola seja considerada lócus de formação de professores e produtora de conhecimento; 3 ) contribuir com o desenvolvimento profissional dos professores da Educação Básica, enquanto processo que se dá ao longo da carreira; 4) promover ações que possibilitem com que os professores da Educação Básica possam constituir-se professores - pesquisadores, a partir de uma postura investigativa. (MP 4, 2014, Art. $1, \S 1)$

Com esses objetivos, fica claro que o MP 4 considera a formação do professor sempre em processo de desenvolvimento e inacabada. Isso significa colocar a participação no mestrado profissional dentro de uma trajetória mais ampla, que começou muito antes do ingresso ao MP e que continuará depois de o professor ter obtido o título de mestre. E, portanto, inclui outros cenários, práticas e discursos. Outra caraterística importante é o interesse em construir vinculações de natureza não hierárquica entre a escola e a universidade. Nessa direção, nos objetivos propostos há evidências de que a escola também é concebida como um locus de aprendizagem e de produção de conhecimentos. Os objetivos também mencionam a noção de professor-pesquisador, neste caso associada à construção de uma postura investigativa, por parte do professor, sobre suas próprias práticas, o que poderia estar vinculado com o desenvolvimento das práticas reflexivas mencionadas anteriormente.

A estrutura curricular do MP 4 estipula uma divisão de créditos entre disciplinas, e a dissertação. Este é, dos quatro MPs selecionados, o que mais créditos outorga à dissertação. Isso indica que ela é considerada como uma das instâncias que possui o maior potencial para desenvolver as aprendizagens docentes esperadas no âmbito do MP 4. As disciplinas estão divididas entre obrigatórias e optativas. Cada mestrando deverá cursar duas obrigatórias e quatro optativas. $\mathrm{O}$ esquema com a análise das disciplinas se mostra na Figura 5.

A partir da observação da Figura 5, pode-se inferir que este mestrado privilegia, através das disciplinas, o desenvolvimento do conhecimento pedagógico geral. Três disciplinas foram categorizadas nesta categoria, já que elas estão focadas nos fundamentos da educação - de caráter obrigatório -, nas teorias do currículo e nas relações entre cultura e tecnologia. Dentro deste MP, o conhecimento matemático e o conhecimento pedagógico do conteúdo aparecem sempre vinculados, e não dissociados, do conhecimento pedagógico geral. Esses pontos não são surpreendentes, já que se trata de um mestrado profissional de caráter generalista, podendo ser cursado por professores de todas as áreas, por coordenadores pedagógicos e gestores das escolas. 


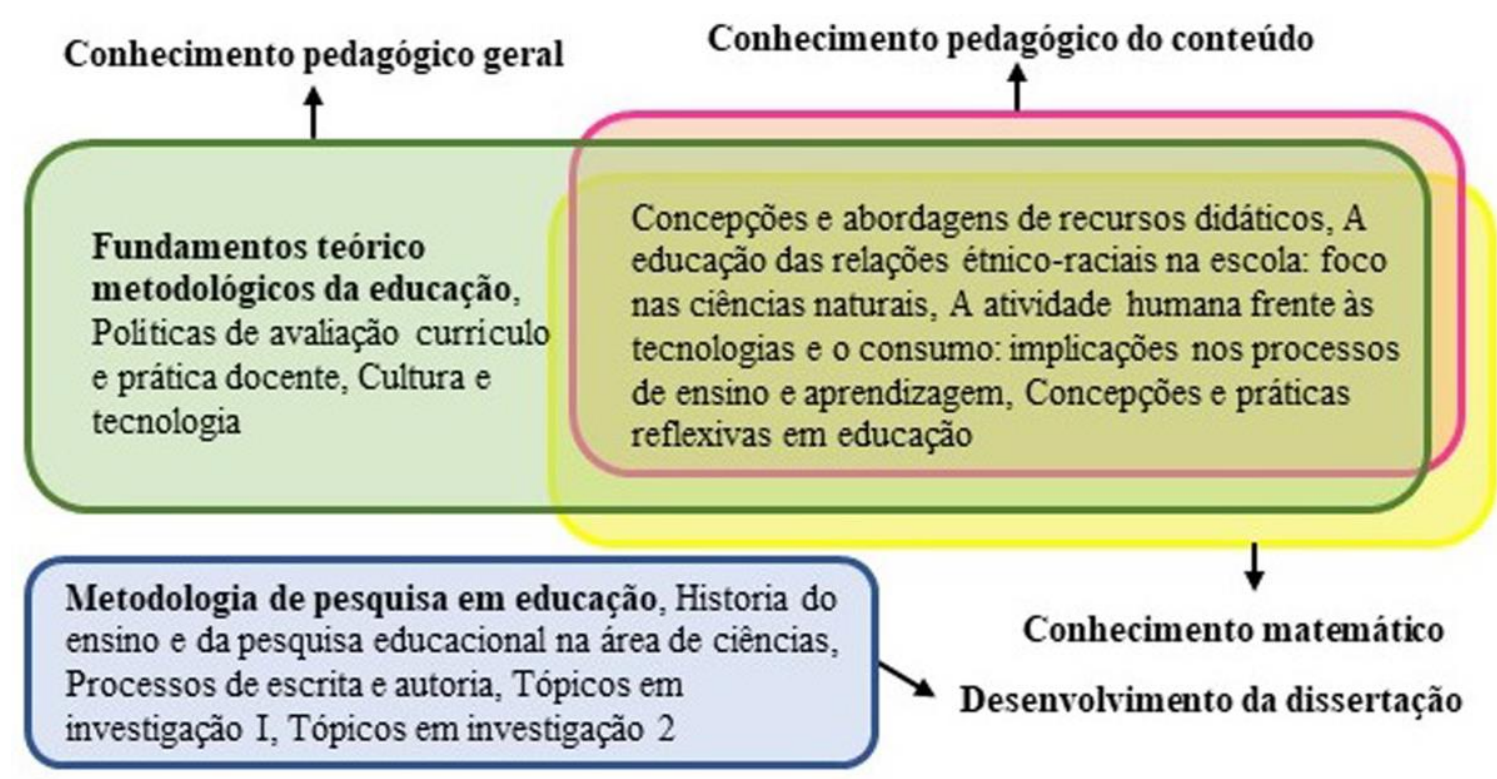

Figura 5. Esquema das disciplinas oferecidas pelo MP 4 Fonte: Os autores

Quatro disciplinas foram categorizadas como pertencentes à interseção entre o conhecimento matemático, o conhecimento pedagógico do conteúdo e o conhecimento pedagógico geral. Por um lado, elas visam desenvolver o conhecimento pedagógico geral, pois trazem discussões sobre as relações étnico-raciais, a formação de cidadãos e as transformações que a sociedade de consumo requer para o âmbito educativo. Por outro lado, elas também propõem a elaboração e a implementação de intervenções em sala de aula ou propiciam a reflexão sobre as práticas docentes dos professores-mestrandos, o que contribuiria com o desenvolvimento do conhecimento matemático e do conhecimento pedagógico do conteúdo ${ }^{8}$. Cinco disciplinas certamente contribuiriam para o desenvolvimento da dissertação, pois estudam os processos de escrita na pesquisa, além das abordagens metodológicas para a pesquisa em educação - tópicos de investigação em educação e do desenvolvimento histórico do ensino - e na área de ciências.

No período de 2014 a 2016 foram defendidas 19 dissertações no total, 6 das quais tratam de problemáticas próprias da Educação Matemática. Quatro dos autores dessas 6 dissertações atuam como professores que ensinam matemática - no Ensino Infantil, Fundamental ou Médio - e os demais são coordenadores pedagógicos ou formadores de professores. Os trabalhos cujos autores atuam como professores envolveram a elaboração de propostas didáticas que logo foram implementadas nas salas de aula em que os professores-mestrandos

\footnotetext{
${ }^{8}$ É importante ressaltar que as ementas destas quatro disciplinas não fazem menção explícita à matemática. Porém, foi realizada a suposição de que professores de matemática trabalhariam com propostas de intervenção em sala de aula que tenham por foco temáticas próprias da matemática e/ou que se envolveriam em reflexões sobre sua prática de ensinaraprender matemática na escola e, portanto, as disciplinas contribuiriam, também, com o desenvolvimento do conhecimento pedagógico do conteúdo e com o conhecimento matemático.
}

\begin{tabular}{l|l|l|l|l|l}
\hline (C) Rev. Inter. Educ. Sup. & Campinas, SP & v.4 & n.2 & p.278-307 & maio/ago. 2018
\end{tabular} 
lecionavam habitualmente. Essas dissertações finalizam com uma análise de todo o processo. Aqueles estudos cujos autores atuam como formadores de professores tiveram por foco a exploração dos significados e das perspectivas que os professores de matemática têm sobre as propostas formativas ou sobre o desenvolvimento curricular de matemática. A partir desta descrição, podemos concluir que, no MP 4, a dissertação se configura como uma oportunidade de aprendizagem focada na reflexão, na análise e/ou na transformação da própria prática docente nas escolas e/ou nos espaços de formação de professores.

Por se tratar de um mestrado de caráter generalista, podemos dizer que o MP 4 privilegia, em certo sentido, um conhecimento para a prática, ligado a diferentes problemáticas e perspectivas pedagógicas, que pode ser aproveitado por professores de diversas disciplinas para melhorar suas práticas. Esse conhecimento seria desenvolvido, na maioria dos casos, por educadores. Mas, desde nosso ponto de vista, essa não é a única nem a principal ênfase formativa do MP 4: a análise realizada nos permite dizer que este curso reconhece e valoriza os conhecimentos que os professores geram na prática docente. Estas ideias, presentes nos objetivos do mestrado, se concretizam com a inclusão de algumas disciplinas principalmente aquela chamada "Concepções e práticas reflexivas em educação" - e ficam evidentes na dissertação. Por sua vez, tanto a dissertação como as disciplinas procuram não somente recuperar esse conhecimento, mas também analisá-lo e problematizá-lo, constituindo, então, oportunidades de aprendizagem com ênfase no desenvolvimento do conhecimento da prática, conforme destacam Cochran-Smith e Lytle (1999).

\section{DISCUSSÃ̃O}

Embora os quatro cursos analisados estejam destinados a professores de matemática, a análise desenvolvida revela que eles sustentam diferentes maneiras de entender o sujeito da formação e suas necessidades formativas. Assim, temos, em primeiro lugar, diferenças em relação ao público alvo, cujo grau de generalidade varia desde professores de matemática no MP 3, professores de matemática e física no MP 1, professores de ciências e matemática no MP 2 e professores que ministram qualquer disciplina da Educação Básica no MP 4. Essas diferenças se refletem na estrutura curricular dos cursos. Particularmente, aqueles cursos destinados a professores que ministram disciplinas variadas enfrentam de maneira diversa a tensão entre atender à especificidade das práticas e discursos próprios do ensino de cada disciplina e, ao mesmo tempo, possibilitar espaços de entendimento comum. Este é um ponto particularmente relevante, quando pensamos em cursos de MP destinados a professores que atuam nos primeiros anos do Ensino Fundamental ou na educação infantil e que, portanto, são professores que ensinam matemática, assim como também ciências e português. Nessa direção, o MP 4 resolve essa tensão oferecendo um conjunto pequeno de disciplinas comuns, orientadas a desenvolver um conhecimento pedagógico que poderia ser aproveitado por professores que ensinam variadas disciplinas e coloca bastante peso na dissertação, na qual 
cada mestrando pode considerar problemáticas próprias da sua prática docente.

Em segundo lugar, podemos notar diferenças em relação às visões sobre os professores que parecem estar sustentando estes quatro espaços formativos. Em alguns casos, parece que a visão do professor-mestrando é a de um profissional que carece de determinados conhecimentos e/ou técnicas e, portanto, o MP se configura como o espaço onde ele deverá adquiri-los para melhorar sua prática docente, independentemente do que já sabe e faz na prática. Em outros casos, o professor-mestrando é concebido como alguém que produz conhecimento a partir de suas experiências na prática docente e encontra no MP um espaço para problematizá-lo e colocá-lo em interlocução com o conhecimento acadêmico. Assim, parece relevante resgatar a ideia - presente nos objetivos do MP 2 e do MP 4 - de formar o professor-pesquisador. Contudo, é importante ressaltar a polissemia da noção do professorpesquisador, compreendido, de um lado, como aquele docente que utiliza e dissemina resultados da pesquisa e que pode formar outros professores no caso do MP 2 ou, de outra forma, como aquele que desenvolve uma postura problematizadora e investigativa sobre suas práticas no caso do MP 4.

Além disso, cada mestrado parece possuir diferentes ênfases formativas: podemos notar diferenças, por exemplo, nas visões sobre o conhecimento de que os professores precisam para ensinar melhor: conhecimento da matemática acadêmica, conhecimento da matemática escolar, conhecimento didático, conhecimento pedagógico, conhecimento sobre suas próprias práticas, etc. Particularmente, nossa análise evidencia que os quatro MP concebem de maneira diversa o papel da matemática dentro do curso. Este tem sido um ponto fortemente discutido no campo das pesquisas sobre professores que ensinam matemática: alguns dos cursos analisados parecem concebidos como espaços formativos dentro da Educação Superior, onde os professores-mestrandos aprendem "mais" matemática. No caso do MP 3 e, em certa medida do MP 1, essa matemática parece ser a matemática acadêmica, sem colocar em primeiro plano o desenvolvimento de vinculações entre esta e aquela que o professor mobiliza nas suas práticas docentes nas escolas. Tal perspectiva contrasta com os achados de diversos pesquisadores que, embora reconheçam a importância do conhecimento disciplinar, também sublinham que ele não é suficiente para a prática de ensinaraprender matemática na escola (BALL; THAMES; PHELPS, 2008; FIORENTINI; OLIVEIRA, 2013; MOREIRA; CURY; VIANNA, 2005). Assim, Ball, Thames e Phelps (2008, p. 404) concluem que o conhecimento da matemática avançada não pode satisfazer todas as demandas do ensino, e os professores precisam ter um conhecimento matemático que lhes permita, entre outras coisas, "produzir sentido matemático sobre o trabalho dos estudantes e escolher maneiras poderosas de representar a disciplina para que seja compreensível para os estudantes”. Desse modo, o ensino da matemática mobiliza um conhecimento matemático específico, que Carrillo et al. (2013) denominam especializado. Quando esse conhecimento não é considerado nas oportunidades de formação, principalmente aquelas destinadas aos professores em serviço, como é o caso dos MP, as possibilidades de impactar na prática docente diminuem, principalmente porque caberá ao professor, atuando de maneira individual e em seus próprios

\begin{tabular}{l|l|l|l|l|c|}
\hline (C) Rev. Inter. Educ. Sup. & Campinas, SP & v.4 & n.2 & p.278-307 & maio/ago. 2018
\end{tabular}


espaços e tempos, construir as vinculações entre a matemática tratada na formação e a matemática que mobiliza cotidianamente em sala de aula.

Constatamos também que cada um dos quatro cursos articula os diferentes conhecimentos de maneira diversa, privilegiando uns, deixando outros em segundo plano e/ou não considerando alguns deles. Particularmente importante é a reflexão em torno das oportunidades para trabalhar simultaneamente os distintos tipos de conhecimentos dentro das disciplinas do mestrado. Desde nosso ponto de vista, atuar em sala de aula envolve mobilizar de maneira articulada conhecimentos matemáticos, conhecimentos pedagógicos e conhecimentos pedagógicos do conteúdo. A estrutura curricular do MP 4, que privilegia nas disciplinas o tratamento articulado desses conhecimentos parece ser uma oportunidade para vincular $\mathrm{o}$ espaço formativo com a vida cotidiana em sala de aula dos professores-mestrandos.

Desse modo, nossa análise mostra que as articulações entre os conhecimentos tratados dentro do mestrado e a vida profissional dos professores-mestrandos nas escolas é variada. Os MP 1, MP 2 e MP 4 parecem oferecer, em distintos graus, possibilidades para que os professoresmestrandos estudem, teorizem problemas e desafios da sua realidade imediata nas escolas e/ou investiguem sobre eles. Portanto, esses cursos constroem inter-relações - em alguns casos mais fortes, em outros mais fracas - entre as práticas formativas adotadas pelos formadores e as demandas das práticas profissionais dos professores-mestrandos. Isso faz com que esses três cursos se constituam como espaços para desenvolver e/ou problematizar os conhecimentos para, na e da prática dos professores-mestrandos, na perspectiva de Cochran-Smith e Lytle (1999) e de Fiorentini e Carvalho (2015). Este ponto parece ser particularmente problemático para o MP 3, visto que as vinculações entre as atividades por ele propostas e a prática profissional dos professores-mestrandos nas escolas parecem ser particularmente frágeis e distanciadas.

Como consequência dessas visões diferentes, também podemos perceber que cada curso entende de maneira diversa quais são as oportunidades que têm o maior potencial para desenvolver aprendizagens docentes desejadas. Em alguns cursos, as disciplinas aparecem como a oportunidade mais privilegiada, porém outros priorizam a dissertação - cujo desenvolvimento pode envolver, ou não, um estágio supervisionado. Essas diferenças se evidenciam no número de créditos outorgados à dissertação e no status que ela tem dentro da estrutura curricular do MP. Tais diferenças regulam, em grande medida, as possibilidades de que a dissertação seja um espaço para que o professor-mestrando realize uma pesquisa sobre suas práticas pedagógicas, tendo a orientação colaborativa do formador da universidade. Este ponto é, segundo nosso entender, de grande relevância, visto que permitiria que os MP se constituíssem como espaços formativos que encurtam as distâncias entre a universidade e a escola, entre a prática acadêmica e a prática escolar.

\section{CONSIDERAÇÕES FINAIS}

Grande parte dos documentos que compõem o corpus analisado neste artigo permite delinear

(C) Rev. Inter. Educ. Sup. Campinas, SP v. 4 n.2

p.278-307

maio/ago. 2018 
o currículo prescrito de cada MP, ou seja, o conjunto de prescrições e orientações do que deve ser o conteúdo desses espaços formativos e das práticas a serem utilizadas no desenvolvimento desses conteúdos (SACRISTÁN, 1998). Os editais de seleção, os regulamentos internos, as grades curriculares e as ementas das disciplinas proporcionam importantes pistas nessa direção. Ao mesmo tempo, nossa análise também incluiu as dissertações defendidas nos MPs no período 2014-2016. Desde nosso ponto de vista, esses documentos são importantes produtos gerados dentro deste currículo prescrito e a partir dele.

Compreendendo o currículo como uma construção social e histórica, da qual participam múltiplos agentes, a análise documental desenvolvida possui limitações, visto que ela não pode nos proporcionar uma visão das práticas educativas e dos conhecimentos que efetivamente se desenvolvem dentro dos MP. Porém, a análise do currículo prescrito destes quatro cursos é relevante, porque ele, ao intervir, organizando e selecionando os conhecimentos e as aprendizagens a serem privilegiados dentro de cada curso, acaba, inexoravelmente, por projetar metodologias de ensino e mediatizar a cultura possível em cada instituição educativa. Assim, a análise documental desenvolvida traz contribuições para o campo da formação de professores no contexto da Educação Superior, pois revela indícios do horizonte das práticas e dos conhecimentos que são possíveis dentro de cada programa de MP. O próximo passo da nossa pesquisa é analisar como esse currículo prescrito se configura e concretiza na prática e trazer as vozes dos professores-mestrandos para narrar as experiências vividas dentro do MP, as dificuldades experimentadas e as contribuições do curso para produzir transformações nas suas práticas docentes e nas suas identidades profissionais.

A análise documental que apresentamos neste artigo aponta indícios de que os MP têm mais chances de se constituir em oportunidades formativas de grande valor, quando sustentam uma visão do professor-mestrando como um profissional que produz um conhecimento experiencial valioso na sua prática docente cotidiana e organizam as atividades curriculares do curso, procurando convertê-las em espaços para pôr em diálogo esse conhecimento com o conhecimento produzido por educadores e educadores matemáticos. Desde esta perspectiva, a teoria acadêmica produzida por pesquisadores nas universidades não poderia ser nem o ponto de partida nem o ponto de chegada dentro do MP, mas um mediador importante que pode ajudar a problematizar, estudar e revelar limites e possibilidades dos conhecimentos produzidos na prática dos professores-mestrandos.

Esta maneira de conceber tanto o sujeito da formação como as respectivas ênfases formativas, embora em consonância com os resultados de variadas pesquisas nacionais e internacionais (COCHRAN-SMITH; LYTLE, 1999; KIERAN et al., 2013; WHITE et al., 2013), não é, ainda, a que costuma sustentar o desenho e a implementação de propostas de formação para professores em exercício. Também não é a que parece estar sustentando todos os cursos de MP que temos analisado neste artigo. Isto coloca um importante desafio para nós, da

\begin{tabular}{l|l|l|l|l|l}
\hline (C) Rev. Inter. Educ. Sup. & Campinas, SP & v.4 & n.2 & p.278-307 & maio/ago. 2018 \\
\hline
\end{tabular}


comunidade de pesquisadores e formadores de professores que trabalhamos na Educação Superior, ressaltando a necessidade tanto de investigar sobre as experiências que realmente estamos oferecendo aos professores dentro dos espaços formativos como de imaginar, propor e implementar mudanças dentro deles, visando transformá-los em instâncias de pesquisa, de produção de conhecimentos e de desenvolvimento da autonomia intelectual do professor. Este desafio se torna ainda mais importante no caso dos MP, visto que eles são espaços formativos que estão convocando cada vez mais docentes.

\section{REFERÊNCIAS}

ANDRÉ, Marli; PRINCEPE, Lisandra. O lugar da pesquisa no mestrado profissional em Educação. Educar em Revista, Curitiba, n. 63, p. 103-117, jan./mar. 2017.

BALL, Deborah Loewenberg; THAMES, Mark Hoover; PHELPS, Geoffrey. Content knowledge for teaching: what makes it special? Journal of Teacher Education, Washington, v. 59, n. 5, p. 389-407, 2008.

BEDNARZ, Nadine; FIORENTINI, Dario; HUANG, Rongjin. International approaches to professional development of mathematics teachers. Ottawa: University of Ottawa Press, 2011.

BRASIL. Ministério da Educação. PORTARIA NORMATIVA No 17, de 28 de dezembro de 2009. Dispõe sobre o mestrado profissional no âmbito da Fundação Coordenação de Aperfeiçoamento de Pessoal de Nível Superior - CAPES. Diário Oficial da República Federativa do Brasil. Brasília, 2009.

CAMPOS, Marília Andrade Torales; GUÉRIOS, Ettiène. Mestrado profissional em Educação: reflexões acerca de uma experiência de formação à luz da autonomia e da profissionalidade docente. Educar em Revista, n. 63, p. 35-51, jan./mar. 2017.

CARNEIRO, Vera Clotilde Garcia. Contribuições para a formação do professor de matemática pesquisador nos mestrados profissionalizantes na área de ensino. Bolema, Rio Claro, v. 21, n. 29, p. 199- 222, 2008.

CARRILO, Jose et al. Determining specialized knowledge for mathematics teaching. In: UBUZ, B.; HASER, C.; MAROTTI, M. A. (Ed.). Proceedings of the Eighth Congress of the European Society for Research in Mathematics Education (CERME 8, February 6 10, 2013). Ankara, Turkey: Middle East Technical University and ERME, 2013. p. 2.9852.994 .

CARVALHO, Dione Luchessi; FIORENTINI, Dario. Refletir e investigar a própria prática de ensinaraprender matemática na escola. In: CARVALHO, D. L.; CRUZ LONGO, C. A.; FIORENTINI, D. (Ed.). Análises narrativas de aulas de matemática. São Carlos: Pedro \& João Editores, 2013. p. 11-23. 
COCHRAN-SMITH, Marilyn; LYTLE, Susan. Relations of knowledge and practice: teacher learning in communities. Review of Research in Education, Washington, v. 24, p. 249-305, 1999.

CRECCI, Vanessa Moreira. Desenvolvimento profissional de educadores matemáticos participantes de uma comunidade fronteiriça entre escola e universidade. 2016. $325 \mathrm{f}$. Tese (Doutorado em Educação) - Programa de Pós-Graduação em Educação, Faculdade de Educação, Universidade Estadual de Campinas, Campinas, 2016.

FIORENTINI, Dario. Learning and professional development of the mathematics teacher in research communities. Sisyphus - Journal of Education, Lisboa, v. 1, n. 3, p. 152-181, 2013.

FIORENTINI, Dario; CARVALHO, Dione Lucchesi de. O GdS como lócus de experiências de formação e aprendizagem docente. In: FIORENTINI, D.; PEREIRA FERNANDES, F. L.; CARVALHO, D. L. (Ed.). Narrativas de práticas e de aprendizagem docente em matemática. São Carlos: Pedro \& João Editores, 2015. p. 15-37.

FIORENTINI, Dario; OLIVEIRA, Ana Teresa de Carvalho Correa. O lugar das matemáticas na licenciatura em matemática: que matemáticas e que práticas formativas? Bolema, Rio Claro, v. 27, n. 47, p. 917-938, 2013.

FLICK, Uwe. Introdução à pesquisa qualitativa. São Paulo: Artmed, 2007.

JAWORSKI, Barbara. Theory and practice in mathematics teaching development: critical inquiry as a mode of learning in teaching. Journal of Mathematics Teacher Education, New York, v. 9, p. 187-211, 2006.

JAWORSKI, Barbara. Building and sustaining inquiry communities in mathematics teaching development. In: KRAINER, K.; WOODS, T. (Ed.). Participants in mathematics teacher education. Rotterdam: Sense Publishers, 2008. p. 309-330.

KIERAN, Carolyn; KRAINER, Konrad; SHAUGHNESSY, Michael. Linking research to practice: teachers as key stakeholders in mathematics education research. In: CLEMENTS, M. A. et al. (Ed.). Third international handbook of mathematics education. New York: Springer, 2013. p. 361-391.

KRIPKA, Rosana; SCHELLER, Morgana; BONOTTO, Danusa Lara. Pesquisa documental: considerações sobre conceitos e caraterísticas na pesquisa qualitativa. In: Atas CIAIQ2015, v. 2. Disponível em: < http://proceedings.ciaiq.org/index.php/ciaiq2015/issue/view/4>. Acesso em: 12 jan. 2018.

LAVE, Jean. The practice of learning. In: CHAIKLIN, S.; LAVE, J. (Ed.). Understanding practice: perspectives on activity and context. New York: Cambridge University Press, 1996. p. 3-32. 
LÜDKE, Menga; ANDRÉ, Marli. Pesquisa em educação: abordagens qualitativas. São Paulo: E.P.U., 1986.

MATOS, Joao Filipe; POWELL, Arthur; SZTAJN, Paola. Mathematics teachers' professional development: processes of learning in and from practice. In: EVEN, R.; BALL, D. L. (Ed.). The professional education and development of teachers of mathematics. New York: Springer, 2009. p. 167-183.

MP 1. Regulamento interno do MP 1, 2008.

MP 3. Regimento interno do MP 3 - Polo A, 2014.

MP 3. Catálogo de disciplinas do MP 3, 2016.

MP 4. Regimento interno do MP 4, 2014.

MOREIRA, Plínio Cavalcanti; CURY, Helena Noronha; VIANNA, Carlos Roberto. Por que análise real na licenciatura? Zetetiké, Campinas, v.13, n.23, p.11-24, 2005.

NERES, Celi Corrêa; NOGUEIRA, Eliane Greice Davanço; BRITO, Vilma Miranda. Mestrado profissional em educação e sua interseção com a qualificação docente na educação básica. RBPG, v. 11, n. 25, p. 885-909, set. 2014.

PIRES, Celia Maria Carolino; INGLIORI, Sonia Barbosa Camargo. Mestrado profissional e o desenvolvimento profissional do professor de matemática. Ciência \& Educação, v. 19, n. 4, p. 1045-1068, 2013.

ROCKWELL, Elsie. La experiencia etnográfica. Buenos Aires: Paidós, 2009.

SACRISTÁN, Juan Gimeno. O currículo: uma reflexão sobre a prática. São Paulo: Artmed, 1998.

SHULMAN, Lee. Those who understand: Knowledge growth in teaching. Educational Researcher, v. 15, n. 2, p. 4-14, 1986.

SHULMAN, Lee. Knowledge and teaching: foundations of the new reform. Harvard Educational Review, v. 57, n. 1, p. 1-21, 1987.

SOUSA, Maria do Carmo. Quando professores que ensinam matemática elaboram produtos educacionais, coletivamente, no âmbito do mestrado profissional. Bolema, Rio Claro, v. 27, n. 47, p. 875-899, dez. 2013.

WHITE, Allan Leslie et al. Teachers learning from teachers. In: CLEMENTS, M. A. et al. (Ed.). Third international handbook of mathematics education. New York: Springer, 2013. p. 393-430. 


\section{Agradecimentos}

Os autores agradecem à Fundação de Amparo à Pesquisa do Estado de São Paulo pelo financiamento da pesquisa através de uma bolsa de pós-doutorado (Processo FAPESP $\mathrm{N}^{0}$ 2016/12877-2).

\section{${ }^{\mathrm{i}}$ Sobre os autores}

\section{Ana Leticia Losano}

E-mail: letilosano@gmail.com / ORCID: https://orcid.org/0000-0002-6120-4926

Universidade Estadual de Campinas - Brasil

Doctora en Ciencias de la Educación pela Universidade Nacional de Córdoba [UNC].

\section{Dario Fiorentini}

E-mail: dariof@unicamp.br / ORCID: https://orcid.org/0000-0001-5536-0781

Universidade Estadual de Campinas - Brasil

Doutor em Educação pela Universidade Estadual de Campinas [UNICAMP]. 